would say that all he requires is a single specification applicable to any rod produced by the manufacturing process. Carter and Robertson would seem to insist that he be provided with a specification descriptive of batches of rods as produced simultaneously by the machines.

In my own treatment ${ }^{2-4} \mathrm{I}$ did, in fact, deal with four-strand recombination and not two-strand. I dealt with exchange points and not with chiasmata as Carter and Robertson assert. Further, I have given various formulæ which in my papers ${ }^{2,3}$ are labelled explicitly as referring to exchange points. These have been quoted by Carter and Robertson (out of context) as referring to chiasmata. As I shall show, this course, which seems to have been adopted as a result of a primary misconception, is likely to lead to error.

My treatment was first developed in terms of an unspecialized interference function $f(t)$, relating to exchange point intercepts, which can be specialized in ways considered most likely to fit experimental data. At the next stage in the argument I selected a special form, $4 t e^{-2 t}$, which remarkably unites two advantages. First, it is mathematically very convenient, and secondly has been found to accord well with empirical evidence ${ }^{2-5}$. Now it so happens that the general theory (prior to specialization) is formally applicable to chiasmata as well as to exchange points. But at the stage where specialization of $f(t)$ becomes necessary, I deliberately chose the form $4 t e^{-2 t}$ as descriptive of exchange points and not of chiasmata. At a critical stage in the construction of their own model, Carter and Robertson find need to insert in their formula some theoretical chiasma statistics, and 'solve' this problem by taking over formulæ of mine (based on the function $4 t e^{-2 t}$ ) which, in fact, were chosen by me as appropriate to exchange point statistics. No critical examination is made of the suitability of these formulæ with regard to empirical justification when applied to chiasmata. To say the least, this slip seems likely to impair the value of the mathematical structure they have erected.

I might add, in conclusion, that at the time my paper was published, I had investigated the compat ibility of the function $4 t e^{-2 t}$ with the mechanism of four-strand exchanges, and confirmed that it was consistent with a variety of models involving different intensities of chromatid and chiasma interference ${ }^{5}$.

Department of Genetics, A. R. G. OWEN Cambridge.

${ }^{1}$ Carter, T. C., and Robertson, A., Proc. Roy. Soc, B, 139, 410 (1952). ${ }^{2}$ Owen, A. R. G., Proc. Roy. Soc., B, 136, 67 (1949).

"Owen, A. R. G., "Advances in Genetics", 3, 117 (1950).

- Owen, A. R. G., Nature, 168, 208 (1951). 'Owen, A. R. G., Ph.D. dissertation, University Library, Cambridge

DR. A. R. G. Owen has developed the mathematical treatment of linear sequential events. He applied it to the occurrence of exchange points in a gamete, that is, those chiasmata at the preceding meiosis in which the strand entering the gamete took part: chiasmata involving only other strands were not considered. To describe this as a four-strand model is true only in so far as three emergent strands are disregarded ; it can equally well be described as a model with two, three or any number of strands. The resulting equations are formally identical with those of a two-strand model ; for this reason chromatid interference, which is a multi-strand phenomenon and of which there is sound eytological evidence ${ }^{1}$, cannot be distinguished from chiasma interference.

This model seemed to us biologically unsatisfactory ; we therefore applied Owen's treatment of sequential events to chiasma formation in a four-strand model, which allowed an explicit treatment of chromatid as well as chiasma interference.

T. C. CARTER Alan Robertson

Institute of Animal Genetics,

West Mains Road, Edinburgh 9.

${ }^{1}$ Huskins, C. L., and Newcombe, H. W., Genetics, 26, 101 (1941).

\section{Computing Machine Terminology}

IN a recent letter in Nature ${ }^{1}$, Prof. R. O. Kapp raises a protest against the use of certain expressions current in the vocabulary of computing machine designers. The chief burden of Prof. Kapp's remarks is directed against the use of anthropomorphic terms, and it is perhaps of interest to see how these arose. The earliest idea for an all-purpose computing machine, in the modern sense, was due to Charles Babbage $^{2}$, who used the terms : mill $=$ portion of machine which operates on numbers; store $=$ portion of machine which holds numbers and emits or absorbs them at the direction of the machine.

When the actual construction of an electronio calculator was first considered, by von Neumann and his group, the logical design was made to depend, to a considerable extent, on what were, at that time, conceived to be the neurological mechanisms of animals. This led to the development of a nomenclature which had the characteristics deprecated by Prof. Kapp.

In fact, most designers (as distinct from the "enthusiasts" of Prof. Kapp) now favour a more down-to-earth vocabulary in which, for example, 'memory' is replaced by the less exceptionable word 'store'. On the other hand, Prof. Kapp is not correct in stating that the words 'setting' and 'adjustment' are synonymous with the 'instruction' and 'teaching' of computer parlance. Neither does the word 'readings' have much relationship to the 'information' given to a computer.

So far as Prof. Kapp's 'code' is concerned, this word is very widely used in computer technology, and the equivalent 'machine language' has been added by linguists and semanticists who have recently 'discovered' these machines.

It has not been possible, in a short note, to consider in detail the technical meaning of the words given above; but it is worth pointing out, in conclusion, that the word 'decision'-or as we prefer it, 'conditional transfer of control'- does not necessarily imply that the machine follows a pre-determined sequence of events. On the contrary, the conditional transfer is frequently used in order that the machine should select between alternative courses of action in a manner which may never become known to the human operator.

ANDREW D. BOOTH

Birkbeck College Computation Laboratory, London, W.C.1. Oct. 16.

${ }^{1}$ Kapp, R. O., Nature, 170, 547 (1952). "Babbage, H. P., “Babbage's Calculating Engines" (Spon and Co., 